\title{
Experimental and Modeling Analysis of Graphite Electrodes with Various Thicknesses and Porosities for High-Energy-Density Li-Ion Batteries
}

\author{
Simon Malifarge, ${ }^{1,2, *}$ Bruno Delobel, ${ }^{2}$ and Charles Delacourt $\oplus^{1, z}$ \\ ${ }^{1}$ Laboratoire de Réactivité et Chimie des Solides, CNRS UMR 7314, Université de Picardie Jules Verne, \\ 80039 Amiens Cedex, France \\ ${ }^{2}$ Renault Technocentre, 78084 Guyancourt, France
}

\begin{abstract}
The influence of the negative electrode design on its electrochemical performance with regard to Li insertion/de-insertion is analyzed in this work. A combined experimental/modeling approach is undertaken relying on Newman continuum model. Various designs of industry-grade graphite electrodes $\left(2-6 \mathrm{mAh} \mathrm{cm}^{-2}\right)$ were previously characterized by measuring geometric and physical parameters that are used as input parameters in the present model analysis. The half-cell model is successfully validated against rate-capability experiments without any further parameter fitting. The various polarization contributions are then identified based on the model analysis of rate-capability tests on the various electrodes. It emerges that low-loading electrodes suffer from larger particle-scale limitations (mainly solid-diffusion limitation) than high-loading electrodes because of a lower active surface area per geometric area. However, high-loading electrodes undergo large liquid-phase limitations at medium to high current densities: a large overpotential develops because of the formation of a large salt concentration gradient across the cell. Finally, the graphite electrode model is used into a full-cell model vs. $\mathrm{LiNi}_{0.33} \mathrm{Mn}_{0.33} \mathrm{Co}_{0.33} \mathrm{O}_{2}(\mathrm{NMC})$ as the positive electrode. Simulations allow for a forecast of the occurrence of Li plating for various cell designs with the constraint of a constant ratio of negative to positive electrode loading.

(C) The Author(s) 2018. Published by ECS. This is an open access article distributed under the terms of the Creative Commons Attribution 4.0 License (CC BY, http://creativecommons.org/licenses/by/4.0/), which permits unrestricted reuse of the work in any medium, provided the original work is properly cited. [DOI: 10.1149/2.0301807jes]

(cc) BY
\end{abstract}

Manuscript submitted February 21, 2018; revised manuscript received April 4, 2018. Published May 1, 2018.

As of today, electric vehicles (EV) are being promoted as a substitute to internal-combustion-engine (ICE) vehicles in an effort to mitigate $\mathrm{CO}_{2}, \mathrm{NO}_{x}$ and particulate matter (PM) emissions from the road transportation sector. Although the effectiveness of EV market penetration toward mitigating air pollution strongly depends upon the source of electricity production (e.g., fossil vs. nuclear or renewable), it may still improve air quality in cities and thereby citizens' health. In fact, the annual cost of air pollution was evaluated to over US\$ 1.431 trillion in Europe by the World Health Organization in 2010. ${ }^{1}$ Nonetheless, the effectiveness of EV market penetration relies on whether consumers are willing to shift from ICE to electric vehicles. Among factors refraining citizens from shifting to EVs are the high price, the vehicle charging time and the driving range. The most straightforward way to tackle both the high price and limited driving range, with state-of-the-art Lithium-ion technology, is to increase electrode loading. Packing more active material in the electrode increases the cell energy density and decreases the amount of inactive material in a Lithium-ion battery pack. Fewer electrodes per stack are needed in a single cell, hence less current collector is used. However, high-loading electrodes suffer large power limitations, which might preclude fast charging of the EV battery pack. Power limitations mostly arise from lithium-ion transport limitations across the electrode porosity filled with the electrolyte and are known to increase with the electrode thickness and/or with a decrease in porosity. ${ }^{2-4} \mathrm{Ac}-$ cordingly, an optimization of the porous electrode design is necessary to achieve a high energy density while retaining enough power for the targeted application.

Yet, electrode design optimization is not straightforward, as it requires performance analysis of a number of different electrode designs. Moreover, a lithium-ion battery (LIB) is a closed system from which only a small number of operating variables can be set and/or measured, e.g., the voltage, the current, and the surface temperature. Electrochemical techniques such as rate-capability tests (galvanostatic charge/discharge at different current densities), electrochemical impedance spectroscopy (EIS), and cyclic voltammetry are regular methods to shed light on cell performance limitations but are unable to give definite insight on any concentration and/or potential gradients forming inside the cell. The experimental investigation of

*Electrochemical Society Student Member

${ }^{\mathrm{z}}$ E-mail: charles.delacourt@u-picardie.fr the influence of electrode loading and density on cell performance is rather scarce in the published literature. Fongy et al. characterized $\mathrm{LiFePO}_{4}$ (LFP) electrodes with different thicknesses, porosity values and binder content by analyzing rate-capability experiments using Prosini's approach. ${ }^{5,6}$ An optimal design was found that balances electronic and ionic limitations that appear at high and low porosity values, respectively. Zheng et al. studied separately the influence of electrode composition, calendering and loading of $\mathrm{Li}\left(\mathrm{Ni}_{1 / 3} \mathrm{Mn}_{1 / 3} \mathrm{Co}_{1 / 3}\right) \mathrm{O}_{2}$ (NMC 111) cathodes by carrying out rate-capability tests and EIS experiments. ${ }^{7-9}$ Ogihara et al. performed EIS on symmetric cells based on graphite electrodes with different loadings, and obtained estimation of charge transfer and ionic resistances. ${ }^{10}$ Shim and Striebel observed that an increased electrode density induces a slight reduction in both the reversible and irreversible capacity for the first cycle of natural graphite. ${ }^{11}$ Buqa et al. examined electrode loadings $(1.5-10 \mathrm{mg}$ $\mathrm{cm}^{-2}$ ) from different synthetic graphites with relatively high electrode porosity $(50-80 \%){ }^{12}$ They showed that the limitation at high C-rate stems from electrode design and not from the graphite material itself. Singh et al. compared rate-capability performance of cathodes and anodes with various loadings. ${ }^{13,14}$ Gallagher et al. also studied cathodes and anodes with various loadings $\left(2.2-6.6 \mathrm{mAh} \mathrm{cm}^{-2}\right)$ and presented a physics-based quantitative relationship to link electrode thickness and rate of operation to performance losses. ${ }^{15}$ Beside studies based on electrochemical techniques, imaging techniques of operando and in-situ cells were developed and allow to provide additional information on local state of charge (SoC) and salt concentration gradient across the cell. ${ }^{16-23}$ However, the analysis turns out to be tedious when screening a large panel of electrode designs.

Mathematical models represent a relevant alternative over experimental time-consuming methods. LIB models are a fast, low-cost and accurate tool to perform electrode design optimization. Providing that model equations represent the underlying physics well enough and that corresponding input parameters are accurate, a LIB model enables to predict what is actually happening inside a cell in terms of, e.g., local SoC and temperature, solid and liquid phase potentials, electronic and ionic current densities and solid/liquid lithium concentration gradients. Moreover, simulated data are easy to handle or display, and power-limitation sources are readily identified by switching on or off the corresponding physical phenomena. Among LIB continuum models, the so-called Newman model offers the best compromise between computation speed and physical significance. It is a pseudo-2D (P2D) model that relies on porous electrode theory and 
concentrated solution theory. ${ }^{24,25}$ The porous electrode is described as the superposition of the liquid and solid phases that are defined by their respective volume fractions and interfacial surface area. Particles of the active material are usually treated as spheres. Model investigation of electrode designs was mainly undertaken using Newman's model. As examples, full-cell optimization for Graphite/LFP ${ }^{26-28}$ and Graphite/ $\mathrm{LiNi}_{0.8} \mathrm{Co}_{0.15} \mathrm{Al}_{0.05} \mathrm{O}_{2}(\mathrm{NCA})^{2}$ were performed by varying cathode thickness and porosity while holding the capacity ratio of the two electrodes constant. The thermal properties of thick electrodes were also studied and compared with that of thin electrodes by combining a 3D thermal model with the P2D model. ${ }^{29,30}$

The aim of the present study is to investigate the performance of various designs of graphite electrodes combining electrochemical characterizations with P2D model simulations. Dedicated experiments are performed on a set of industry-grade graphite electrodes to determine all model parameters pertaining to the graphite electrode, i.e., geometric and physical parameters. Other model parameters such as electrolyte and separator properties are taken from the literature. Moreover, the lithium diffusion coefficient in the solid phase, the reaction-rate constant and the electrolyte properties are taken to be dependent on the lithium concentration, which is in harmony with experimental facts. ${ }^{31-35}$ Indeed, the assumption of parameter invariance with concentration falls short for high-loading electrodes where large concentration gradients form even at moderate C-rate in the liquid phase across the cell and in the solid phase across the electrodes. However, composition-dependent properties may complicate the model convergence, hence calling for an increase of the number of nodes across the cell sandwich and/or across the radial dimension of the active particles, along with a decrease of the time step, which is at the expense of simulation time.

P2D model simulations are first validated against rate-capability tests performed up to $3 \mathrm{C}$ on the set of industry-grade electrodes using $\mathrm{Li} /$ graphite half cells. Note that there is no parameter fitting based on the rate-capability data. The influence of the electrode pore tortuosity is assessed using the model through a comparison between measured tortuosity value and that predicted using Bruggeman's relation. Results of the rate-capability tests are then analyzed with the help of a model analysis, which consists in breaking down the electrode overpotential into each polarization source for a low and a high loading electrode design. Results obtained from this model-based analysis are eventually discussed. Finally, as a perspective of this work, the occurrence of $\mathrm{Li}$ plating at the graphite electrode is assessed for various electrode designs in a full-cell setup versus a NMC 111 positive electrode. A negative-to-positive ratio of areal capacity (also referred to as balancing) of 1.1 is set and the occurrence of $\mathrm{Li}$ plating is probed at two different current densities.

\section{Experimental}

The set of graphite electrodes studied in this work is provided by an industrial partner. A total of sixteen electrodes is investigated (see Figure 1) that is comprised of four separate loadings (L1: 1.8; L2: 3.3; L3: 4.4; L4:5.9 $\mathrm{mAh} \mathrm{cm}^{-2}$ ) and four different porosities, between 40 and $10 \%$ and noted D1 to D4. Hereafter, electrodes are referred by their name corresponding to their loading and density, e.g., electrodes of the first loading $\left(1.8 \mathrm{mAh} \mathrm{cm}^{-2}\right)$ and first density (largest porosity, 40\%) are denoted L1D1. Iso-loading electrodes originate from the same batch and are set to different densities by calendering to different targeted thicknesses, thereby decreasing their porosity. The composition of the electrodes is $97 \% \mathrm{wt}$ of graphite, $1 \% \mathrm{wt}$ of carboxy-methyl cellulose (CMC), $1 \%$ wt of styrene-butadiene rubber (SBR), and $1 \%$ wt of conductive carbon. The current collector is made of copper. The specific capacity of the graphite material is measured by cycling a low-loading electrode $\left(1.2 \mathrm{mAh} \mathrm{cm}^{-2}-\right.$ porosity $40 \%$ ) versus lithium metal (Sigma-Aldrich) between 0.005 and $1.5 \mathrm{~V}$ vs Li at a C-rate of C/50; a reversible capacity between 360 and $370 \mathrm{mAh} \mathrm{g}^{-1}$ is obtained. The experiments are conducted in coin cells vs. a lithium counter electrode (CE). The working electrode

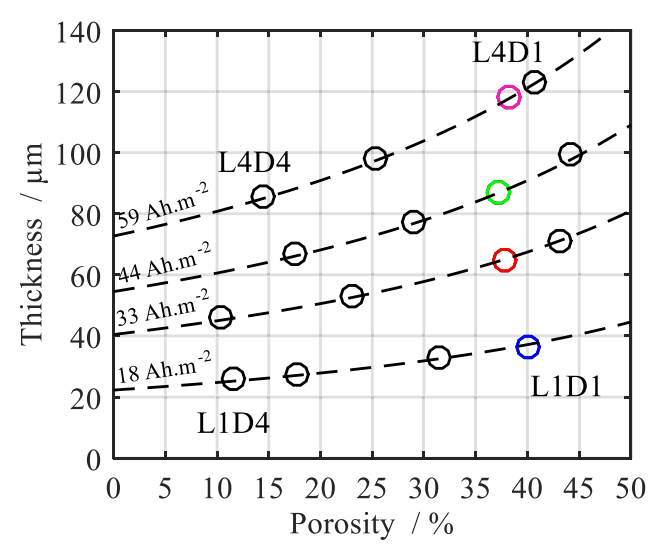

Figure 1. Thicknesses and porosities of the different graphite electrode designs studied in this work. Figures 7 to 11 refer to the electrode designs represented with colored circles.

(WE) and lithium CE areas are ca $1.5 \mathrm{~cm}^{2}$ and the separator is a trilayer coated polymeric separator disk (SKi NV00) punched at $2 \mathrm{~cm}^{2}$. The selected electrolyte is EC:DEC $(1: 1 \mathrm{wt} \%)$ with $1 \mathrm{~mol} \mathrm{~L}^{-1} \mathrm{LiPF}_{6}$ (LP 40) because its transport properties were estimated by Lundgren et al. $^{35}$ and other studies also report similar values. ${ }^{36,37}$ The electrodes and cell parts are dried overnight at $80^{\circ} \mathrm{C}$ in a vacuum oven and the coin cells are assembled in an argon filled glove box $\left(\mathrm{O}_{2}\right.$ $<0.1 \mathrm{ppm}, \mathrm{H}_{2} \mathrm{O}<0.1 \mathrm{ppm}$ ). During cell assembly, a small vacuum $(\Delta P=0.05$ bar) is applied during ca $1 \mathrm{~min}$ after electrode wetting to ensure better electrolyte impregnation. Cells are further kept overnight at $45^{\circ} \mathrm{C}$ before any cycling.

Rate-capability tests are performed on a VMP3 (Bio-Logic, France) at $25^{\circ} \mathrm{C}$. Cells are first cycled four times with constant-current (CC) discharge/charge cycles at $\mathrm{C} / 10$ to form a solid-electrolyte interphase (SEI) at the graphite particle surface. The formation is followed by a constant-current-constant-voltage (CCCV) protocol at C-rates ranging from $\mathrm{C} / 50$ to $3 \mathrm{C}$ between $0.005 \mathrm{~V}$ and $1.5 \mathrm{~V}$ vs Li. During the CV steps, the cell potential is held constant at both cutoff voltages until the current gets down to C/50. For $1 \mathrm{C}, 2 \mathrm{C}$, and $3 \mathrm{C}$, two discharge/charge cycles are performed instead of just one for repeatability sake. Finally, after the rate-capability test, two C/10 cycles are run to spot any possible electrode degradation.

The cell modeled in this study consists of a lithium foil, a separator and a graphite electrode all soaked in LP40 electrolyte. Graphite particles are assumed spherical though their actual shape resembles potatoes. The model equations used in this paper are those described previously by Newman's group. ${ }^{24,25}$ In the porous electrode, mass balances on the lithium concentration in the solid and liquid phases are coupled via the reaction rate at the solid-liquid interface using the Butler-Volmer equation. The electrochemical reaction is distributed over the surface of the active-material particles, and varies across the depth of the electrode due to the interaction of local surface overpotential and concentration changes in both the liquid and solid phases. A current balance relates the ionic current density to the pore-wall flux. An Ohm's law and an extended Ohm's law account for the potential distribution in the solid and liquid phases, respectively. The lithium foil electrode is considered as a boundary where the anion flux is zero and the Butler-Volmer equation links the rate of the electrochemical reaction to lithium salt concentration and liquid/solid potentials. No double layer capacitance or surface films (SEI) are considered in the present study, neither at the lithium foil nor at the graphite particle surface. Possible resistive contributions of SEIs are artificially lumped into the graphite and lithium rate constants for charge transfer, which were fitted to electrochemical data with the same assumption of neglecting the SEIs in previous studies. ${ }^{38,39}$

As mentioned in the introduction, parameters pertaining to the graphite electrodes are directly measured or estimated from dedicated experiments combined with model analysis. ${ }^{39-41}$ Other model 


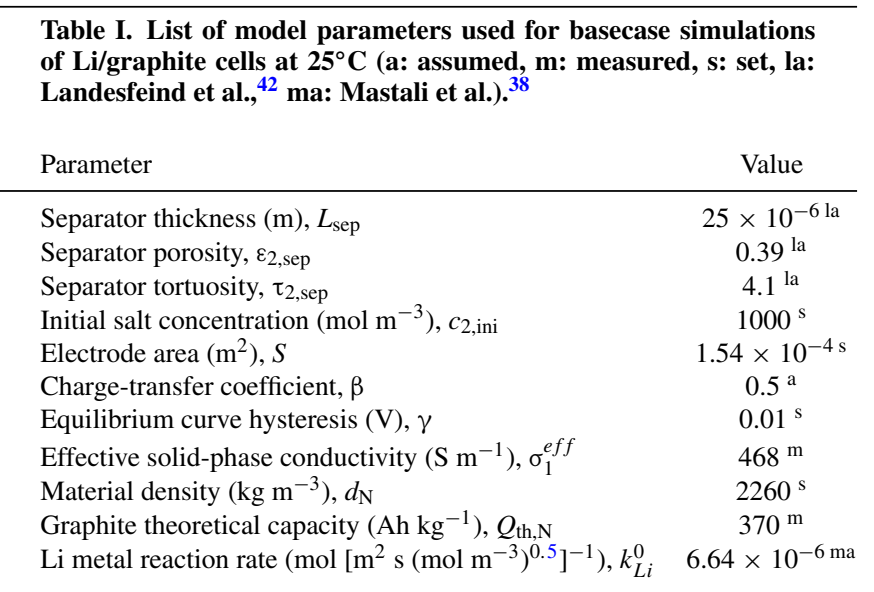

parameters are taken from measurements found in the literature. Electrolyte properties reported by Lundgren et al. are extrapolated from $[0.5-1.5] \mathrm{mol} \mathrm{L}^{-1}$ to $[0-2] \mathrm{mol} \mathrm{L}^{-1} .35$ They are represented as a function of concentration in supplemental material (Figure S1). Values for the separator thickness, porosity, and tortuosity are taken from Ref. 42. The reaction-rate constant at the lithium foil was measured by Mastali et al. to be $6.64 \times 10^{-6} \mathrm{~mol}\left[\mathrm{~m}^{2} \mathrm{~s}\left(\mathrm{~mol} \mathrm{~m}^{-3}\right)^{0.5}\right]^{-1}$ at $23^{\circ} \mathrm{C} .{ }^{38}$ It is determined from data analysis of a lithium symmetric cell cycled at various current densities. Similar experiments carried out in house yielded a similar value at $25^{\circ} \mathrm{C}$ (not shown here). Some of the model parameters are provided in Table I.

Graphite electrode properties are measured via multiple techniques. The particle-size distribution (PaSD) of the graphite powder is determined by acoustic measurement (DT1202, Dispersion Technology Inc) performed on the electrode slurry. An ultrasound attenuation spectrum of the sample is measured and analyzed based on the acoustic theory. The PaSD has a d50 value of $19.5 \mu \mathrm{m}$. The histogram of the PaSD for 10 particle bins is available in supplemental material (Figure S2). Electrode thickness is measured on cross-section images obtained by optical-microscopy observations of electrode samples that are impregnated with a low viscosity epoxy-resin solution and polished. Observations of the 16 electrode designs are available in supplemental material (Figure S3). Mean electrode porosity is evaluated from weight and composition. Electrode pore tortuosity values are estimated by dedicated EIS experiments on graphite symmetric cells. Details of the experimental and modeling analysis and resulting pore tortuosity values for all the electrodes are published in Ref. 40. Graphite equilibrium curve is determined from the galvanostatic intermittent titration technique (GITT) performed on a thin porous electrode $\left(1.2 \mathrm{mAh} \mathrm{cm}^{-2}-\right.$ porosity $\left.40 \%\right)$ in Li/graphite coin cells. Twenty current pulses at $\mathrm{C} / 20$, each followed by a $15-\mathrm{hr}$ rest period are measured upon lithium insertion/deinsertion into/from graphite. Pulse duration is adjusted to better define the slanted parts of the equilibrium curve. Although a hysteresis on relaxed potentials between graphite reduction and oxidation equilibrium curves is observed, a single averaged equilibrium curve is taken to simulate both charge and discharge, and $\mathrm{a} \pm 10 \mathrm{mV}$ hysteresis is then added accordingly to the simulated potential curve depending on the current sign. The graphite equilibrium curve is provided in supplemental material (Figure S4). The reactionrate constant and solid diffusion coefficient of graphite are determined from the fit of potentiostatic intermittent titration technique (PITT) data measured on the same thin porous electrode design in Li/graphite cells. Details about the procedure are given in Ref. 39. Plots of the reaction-rate constant and solid-diffusion coefficient as a function of the fraction of inserted lithium are reproduced in supplemental material (Figure S5). These two composition-dependent paremeters are implemented as lookup tables in the model, and linear interpolation is performed so that the parameter variation is continuous with composition. The effective solid-phase conductivity is measured by performing EIS experiments on a delaminated piece of the L4D1 electrode

\section{Table II. List of model parameters used for full-cell simulations at}

$25^{\circ} \mathrm{C}$ for $\mathrm{Li}$ plating predictions (s: set).

Parameter Value

Graphite $(\mathrm{N})$
Electrode thickness $(\mathrm{m}), L_{\mathrm{N}}$
Pore tortuosity, $\tau_{2, \mathrm{~N}}$
Initial stoichiometry, $x_{\mathrm{i}, \mathrm{N}}$
$N M C(\mathrm{P})$
Electrode thickness (m), $L_{\mathrm{P}}$
Negative-to-positive loading
balancing
Active material fraction, $\varepsilon_{\mathrm{AM}, \mathrm{P}}$
Liquid-phase fraction, $\varepsilon_{2, \mathrm{P}}$
Particle radius (m), $r_{\mathrm{P}}$
Solid-phase conductivity $\left(\mathrm{S} \mathrm{m}^{-1}\right), \sigma_{\mathrm{P}}$
Material density $\left(\mathrm{kg} \mathrm{m} \mathrm{m}^{-3}\right), d_{\mathrm{P}}$
NMC theoretical capacity $\left(\mathrm{Ah} \mathrm{kg}^{-1}\right)$,
$Q_{\text {th, } \mathrm{P}}$
Reaction-rate constant $\left(\mathrm{mol}^{-1} \mathrm{~m}^{2} \mathrm{~s}\right.$
$\left.\left.\left(\text { mol } \mathrm{m}^{-3}\right)^{1.5}\right]^{-1}\right), k_{\mathrm{P}}^{0}$
Initial stoichiometry, $x_{\mathrm{i}, \mathrm{P}}$

$\left(S=0.17 \mathrm{~cm}^{2}-L=123 \mu \mathrm{m}\right.$, porosity $\left.42 \%\right)$. Its value is $468 \mathrm{~S} \mathrm{~m}^{-1}$ at $25^{\circ} \mathrm{C}$, which is far much larger than the bulk electrolyte conductivity of $\mathrm{LP} 40$ at $25^{\circ} \mathrm{C}\left(\kappa=0.79 \mathrm{~S} \mathrm{~m}^{-1}\right.$ at $\left.1 \mathrm{~mol} \mathrm{~L}^{-1}\right)$ and therefore has no influence on the simulations, i.e., there is virtually no potential gradient across the solid phase of the electrode. The effective solid-phase conductivity is supposed to be electrode-design dependent, however, the same value is used for all electrodes in this work, keeping in mind that it has a negligible influence on the simulations.

As a perspective of this work, $\mathrm{Li}$ plating at the graphite electrode is studied in a last section. A full-cell model is used combining parameters of the graphite electrode, separator, and electrolyte as described above with parameters for a NMC positive electrode, which are either taken from the literature or set. Full-cell simulation parameters are displayed in Table II. Different graphite-electrode designs are probed for loadings of 1 up to $6 \mathrm{mAh} \mathrm{cm}^{-2}$ and porosities ranging between $10 \%$ and $50 \%$. The positive electrode loading is adjusted to be dependent on that of the graphite electrode so as to keep a negative-to-positive balancing of 1.1. Pore tortuosity of the graphite electrodes is estimated from the equation indicated in Table II which was obtained from a power-law fit of measured tortuosity values of all 16 electrode designs that we studied experimentally. ${ }^{40}$ The Bruggeman relation is used to estimate tortuosity values of the solid and liquid phases in the positive electrode since NMC particles are assumed spherical. The initial stoichiometry of the positive electrode is set to 0.94 so as to account for a cyclable Li loss due to SEI formation at the graphite electrode. A variable solid-diffusion coefficient is considered for the positive electrode and taken from Ref. 43 and a single particle size is set. Two current densities are analyzed, namely 1 and $2 \mathrm{~mA} \mathrm{~cm}^{-2}$. Li plating is likely to occur at a location in the graphite electrode if the local difference between the solid and liquid phase potentials becomes negative. The cell potential cutoff upon charge is set to $4.3 \mathrm{~V}$ vs Li.

\section{Results and Discussion}

Experimental vs model simulations.-P2D model simulations are compared with rate-capability experiments for each electrode design. Only geometric parameters vary from one design to the other, i.e. the electrode thickness, porosity, AM fraction, and liquid-phase tortuosity. Simulations for which local salt concentration reaches $2 \mathrm{~mol} \mathrm{~L}^{-1}$ somewhere across the cell sandwich are interrupted. In this situation, simulated values of the cell overpotential may still serve for comparison with experiments, whereas values of the delivered areal capacity are irrelevant and discarded. Beyond the $2 \mathrm{~mol} \mathrm{~L}^{-1}$ threshold, the liquid-phase transport properties are not reported in the literature, 

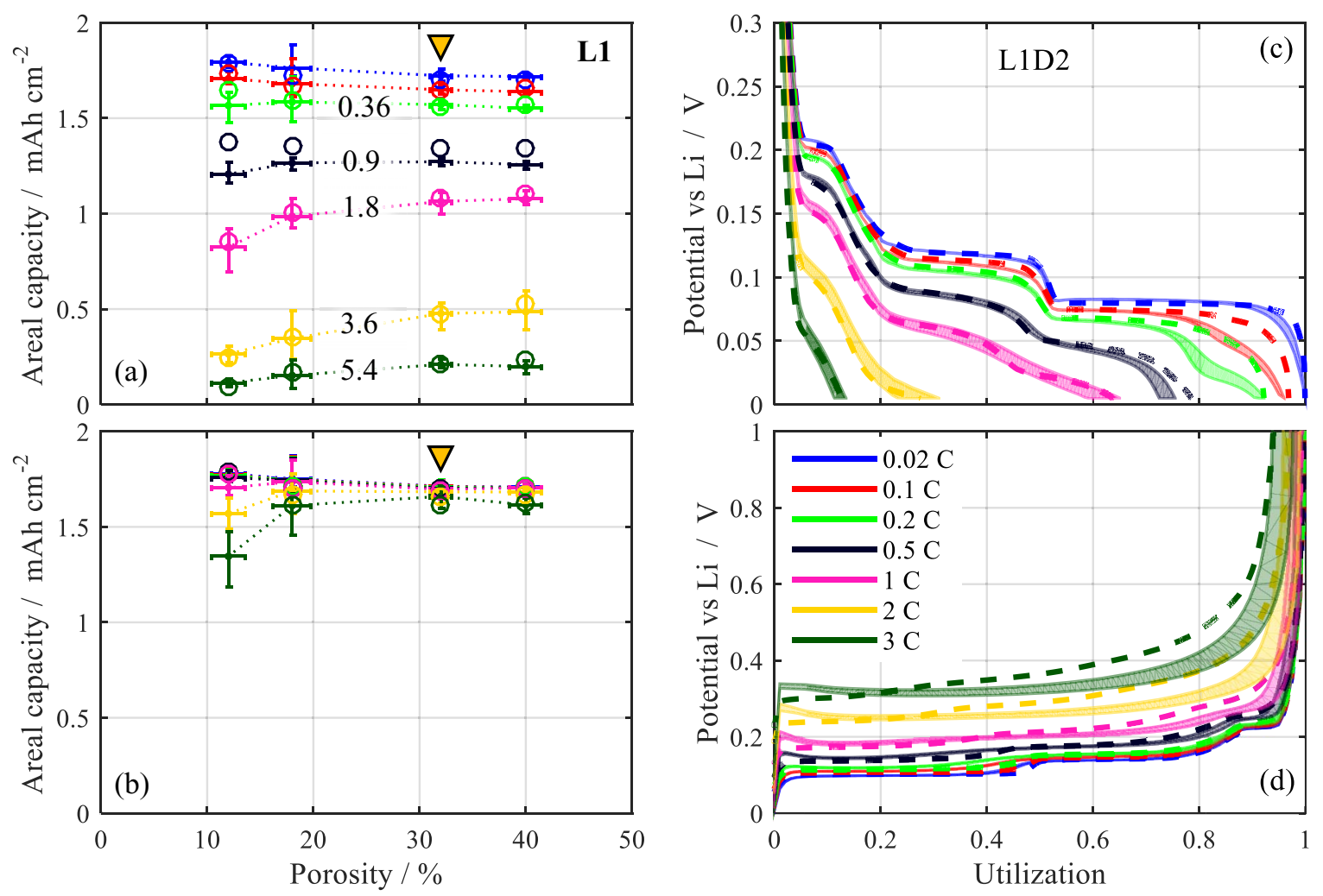

Figure 2. (a)-(b) Areal capacity values delivered upon galvanostatic cycling for the L1 electrodes (dotted lines) compared with P2D model simulation results (circles) for graphite reduction and oxidation, respectively. Current densities $\left(\mathrm{mA} \mathrm{cm}^{-2}\right)$ corresponding to the C-rates are written on top of the dotted lines. (c)-(d) Galvanostatic curves corresponding to the designs marked by the yellow triangles in (a)-(b) are represented for both experimental measurements (envelope curves) and P2D model simulations (dash lines). The C-rate color code is the same for all subplots.

hence it is not meaningful to run simulations in these conditions. In all figures represented hereafter, curve envelopes represent variability in a number of experimental repeats. For the sake of conciseness, the normalized capacity by that at $\mathrm{C} / 50$ is referred to as utilization hereafter.

The model is first validated against the L1 electrodes $\left(1.8 \mathrm{mAh} \mathrm{cm}^{-2}\right)$ that are expected to undergo only small liquid-phase limitation. Comparisons of measured galvanostatic curves and resulting areal capacities with corresponding P2D model simulations for this electrode loading are displayed in Figure 2. Experimental and simulated data match well in terms of both cell overpotential and areal capacity for all four porosity values (D1 to D4) and at almost all C-rates. Upon graphite reduction from $\mathrm{C} / 10$ to $\mathrm{C} / 2$ in Figure $2 \mathrm{c}$, differences between simulations and experiments are visible near the end of lithium insertion on stage-1 plateau. An additional overpotential is visible in the experiments (especially at $\mathrm{C} / 5$ ) that causes the cell potential to reach the cutoff prematurely, hence decreasing the measured capacity value. This phenomenon is not visible beyond a current-density threshold because the cutoff potential is reached before it starts to show up. The reason for this additional overpotential was separately investigated by performing 3-electrode experiments with a lithium reference electrode placed in between two separators (details about the three-electrode measurement provided in the caption of Figure S6). The galvanostatic reduction curve of the 3-electrode data is shown in supplemental material (Figure S6). From this experiment, the additional overpotential in the two-electrode cell is ascribed to an increase of the potential of the $\mathrm{CE}$ from a certain depth of discharge onward. The root cause is yet to be investigated, but is beyond the scope of this work. Upon graphite oxidation from $1 \mathrm{C}$ to $3 \mathrm{C}$ in Figure 2d, small potential differences between simulations and experiments are observed. The experimental curves are rather flat whereas simulated potential curves gradually increase. This discrepancy is discussed in the Model analysis section. Overall, the match between experiments and simulations is satisfactory, keeping in mind that there is no fitted parameter to simulate the galvanostatic curves in this work. It attests for the effectiveness of the physics-based model, in which input parameters are measured independently on different electrode designs and with different (electrochemical) methods, or even taken from literature.

The model is now validated against the $\mathrm{L} 2, \mathrm{~L} 3$, and $\mathrm{L} 4$ electrodes (loadings of 3.3, 4.4, and $5.9 \mathrm{mAh} \mathrm{cm}^{-2}$, respectively). Comparisons of measured galvanostatic curves and resulting areal capacities with P2D model simulations for these electrode loadings are displayed in Figures 3 and 4 for graphite reduction and oxidation, respectively. Concerning graphite reduction in Figure 3, experimental and simulated data match well in terms of both cell potential and areal capacity at almost all C-rates and for all electrode designs except L3D4 and L4D4 (see Figures 3b-3c). L3D4 and L4D4 undergo less liquid-phase polarization than what is predicted by the model (not shown here). Their experimental potential and delivered areal capacity are on par at each C-rate with those of the more porous electrode designs L3D3 and L4D3, respectively. One way to reconcile the model simulations with experiments for these two electrode designs is to lower the pore tortuosity in the model to a value of ca 4 . It is possible that these two designs suffer nonuniformities in some properties, so as porosity and/or tortuosity, but we could not investigate this hypothesis further. Beside these two electrode designs and similarly as described above for L1, an additional overpotential also appears upon reduction on the stage 1 plateau at medium C-rates for L2, L3, and L4 electrode loadings (Figures 3d-3f), hence leading to an underestimation of some measured areal capacity values reported in Figures $3 a-3 c$. Concerning graphite oxidation in Figure 4, experimental and simulated data match well in terms of both cell potential and corresponding areal capacity for current densities under ca $2 \mathrm{~mA} \mathrm{~cm}^{-2}$ and for all designs except for L3D4 and L4D4 electrodes again. P2D simulations and experiments still match for low-to-medium extent of graphite oxidation 

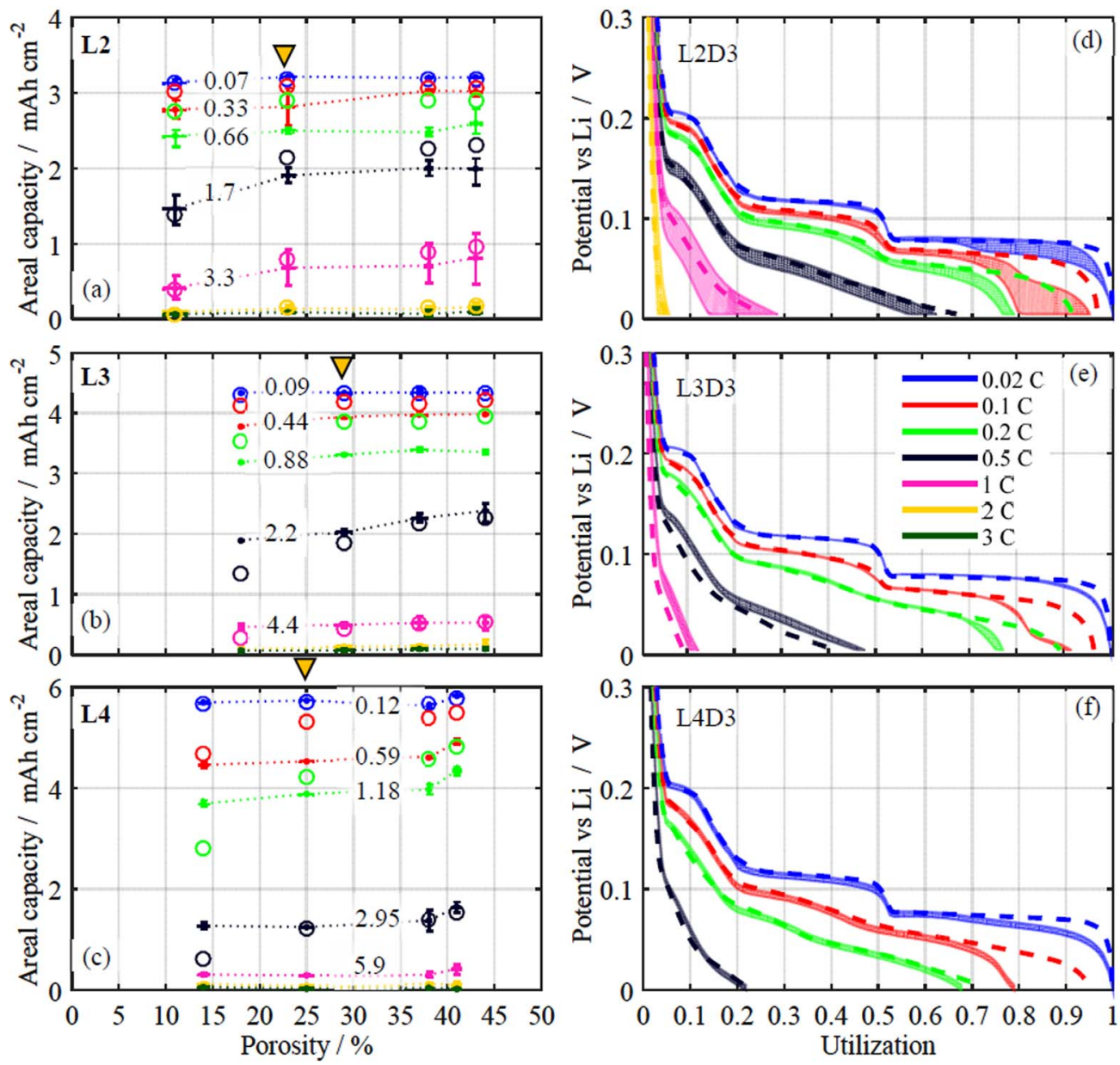

Figure 3. (a)-(b)-(c) Areal capacity values delivered upon galvanostatic graphite reduction for L2-L3-L4 electrodes (dotted lines) compared with P2D model simulation results (circles). Current densities $\left(\mathrm{mA} \mathrm{cm}^{-2}\right.$ ) corresponding to the C-rates are written on top of the dotted lines. (d)-(e)-(f) Galvanostatic reduction curves corresponding to the designs marked by the yellow triangles in (a)-(b)-(c) are represented for both experimental measurements (envelope curves) and P2D model simulations (dash lines). The C-rate color code is the same for all subplots.

until ca $5 \mathrm{~mA} \mathrm{~cm}^{-2}$. Beyond this threshold value, there is no match at all; the experimental shoot up in potential (up to $1.5 \mathrm{~V}$ vs. Li) is incorrectly predicted by the model. Upon oxidation, the phenomenon involved in this sudden shoot in cell potential may either be linked to: (i) a drop of the Li solid-phase concentration to zero at the surface of the graphite particles; (ii) high local salt concentration in the electrode inducing either a decrease in local electrolyte conductivity (due to an increase in viscosity) to an extent where it may lead to salt precipitation; (iii) a drop of salt concentration to zero at the $\mathrm{Li}$ CE surface. For L1 electrodes, model analysis reveals that the oxidation simulation prematurely ends at high C-rate (Figure $2 \mathrm{~d}$ ) because the Li solid-phase concentration drops to zero at the surface of the graphite particles (Figure 5b). Hence, mechanism (i) is relevant to describe the experimental shoot in potential observed for L1 electrode designs. However, for L2, L3, and L4 electrodes, the premature shoot up in potential at high C-rate in the simulations (see Figures $4 d-4 f$ ) occurs because salt concentration drops to zero on the Li CE side (Figure $5 \mathrm{c}$ ). In this situation, a mismatch is observed between experiments and model simulations (Figures $4 d-4 f$ ), i.e. the model may not describe properly mechanism (iii). A possible reason for this discrepancy is that the Li plating/stripping mechanism at the (assumed) flat $\mathrm{Li}$ metal CE is oversimplified in the model. Further discussion on this topic is addressed in the Model analysis section.

To conclude on the model validation against rate-capability tests, P2D model simulations match well upon graphite reduction at all C-rates and for all electrode designs except L3D4 and L4D4. For graphite oxidation, model simulations match well in terms of both potential and areal capacities for the L1 loading at all tested C-rates $\left(<5.4 \mathrm{~mA} \mathrm{~cm}^{-2}\right)$ and for the L2, L3, and L4 loadings until current densities of ca $2 \mathrm{~mA} \mathrm{~cm}{ }^{-2}$. Above this threshold, for these highloading electrodes, cell potentials still match until ca $5 \mathrm{~mA} \mathrm{~cm}-2$ but only for low-to-medium extent of graphite oxidation. At large extent of graphite oxidation, model simulations either show a full utilization or interrupt because local salt concentration rises above $2 \mathrm{~mol} \mathrm{~L}-1$ somewhere in the graphite electrode. For current densities above ca $5 \mathrm{~mA} \mathrm{~cm}{ }^{-2}$, an experimental/simulated data mismatch is clearly visible at any extent of graphite oxidation. Model simulations are found to end because salt concentration drops to zero at the Li CE surface (e.g., Figure 5c). Besides, for current densities of ca $3 \mathrm{~mA} \mathrm{~cm}^{-2}$ or more, it is observed that the measured areal capacities decrease further for low-porosity electrodes at a specified loading (see Figures $4 \mathrm{a}-4 \mathrm{c})$ compared with high-porosity electrodes. Hence, it implies that this areal capacity decrease and subsequent experimental shoot up in potential are, to a certain extent, partially related to liquidphase limitations. Galvanostatic simulations and experiments at high current densities for the L2, L3, and L4 loadings all point toward this conclusion.

Influence of pore tortuosity value.-In this section, simulations are performed using pore tortuosity values calculated from the Bruggeman relation $\left(\tau=\varepsilon^{-0.5}\right)$ instead of those determined from EIS analysis of symmetric cells. ${ }^{40}$ Two examples are laid out in Figure 6 for the 

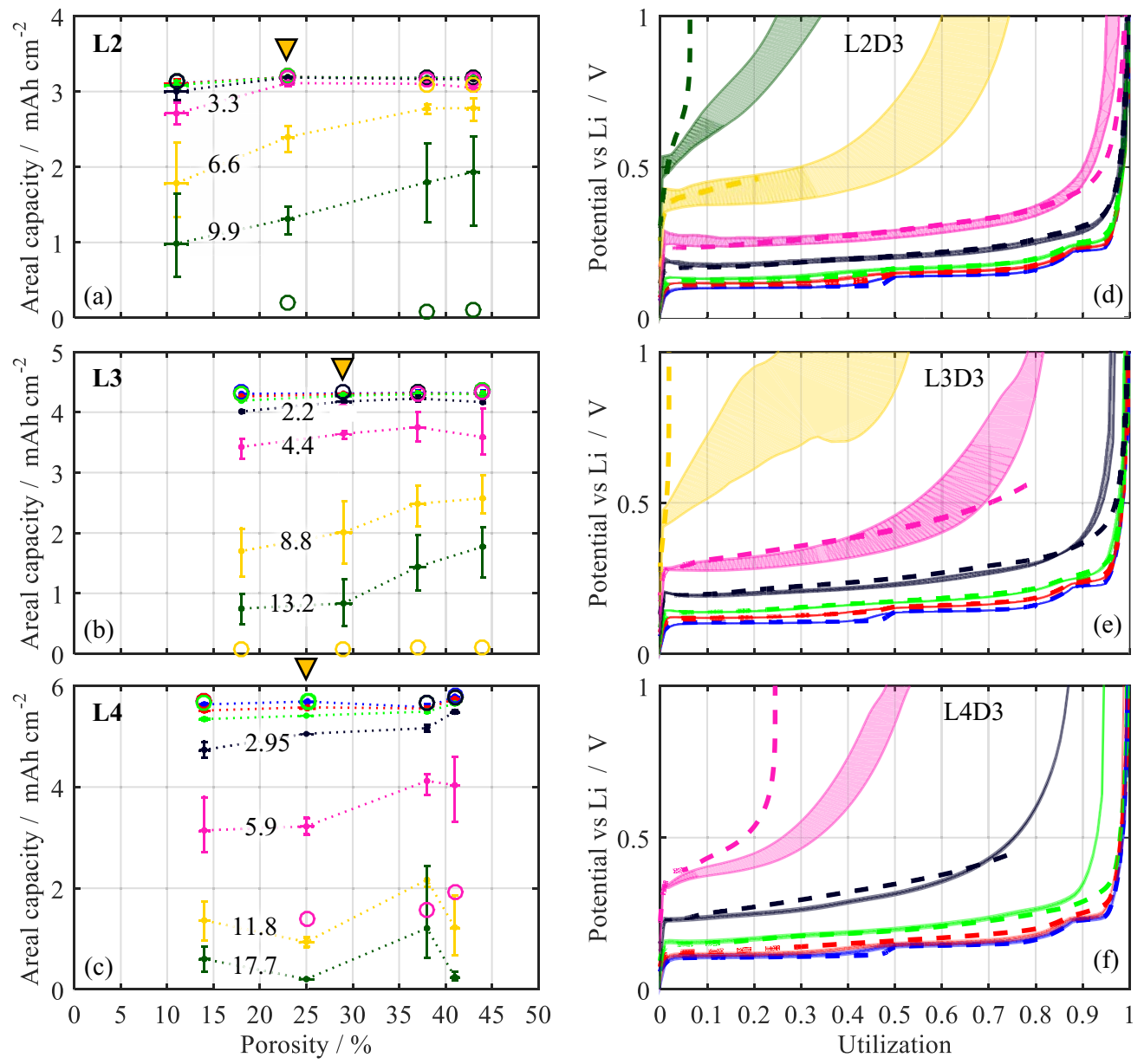

Figure 4. (a)-(b)-(c) Areal capacity values delivered upon galvanostatic graphite oxidation for L2-L3-L4 electrodes (dotted lines) compared with P2D model simulation results (circles). Current densities $\left(\mathrm{mA} \mathrm{cm}^{-2}\right.$ ) corresponding to the C-rates are written on top of the dotted lines. (d)-(e)-(f) Galvanostatic oxidation curves corresponding to the designs marked by the yellow triangles in (a)-(b)-(c) are represented for both experimental measurements (envelope curves) and P2D model simulations (dashed lines). The $\mathrm{C}$-rate color code is the same for all subplots.
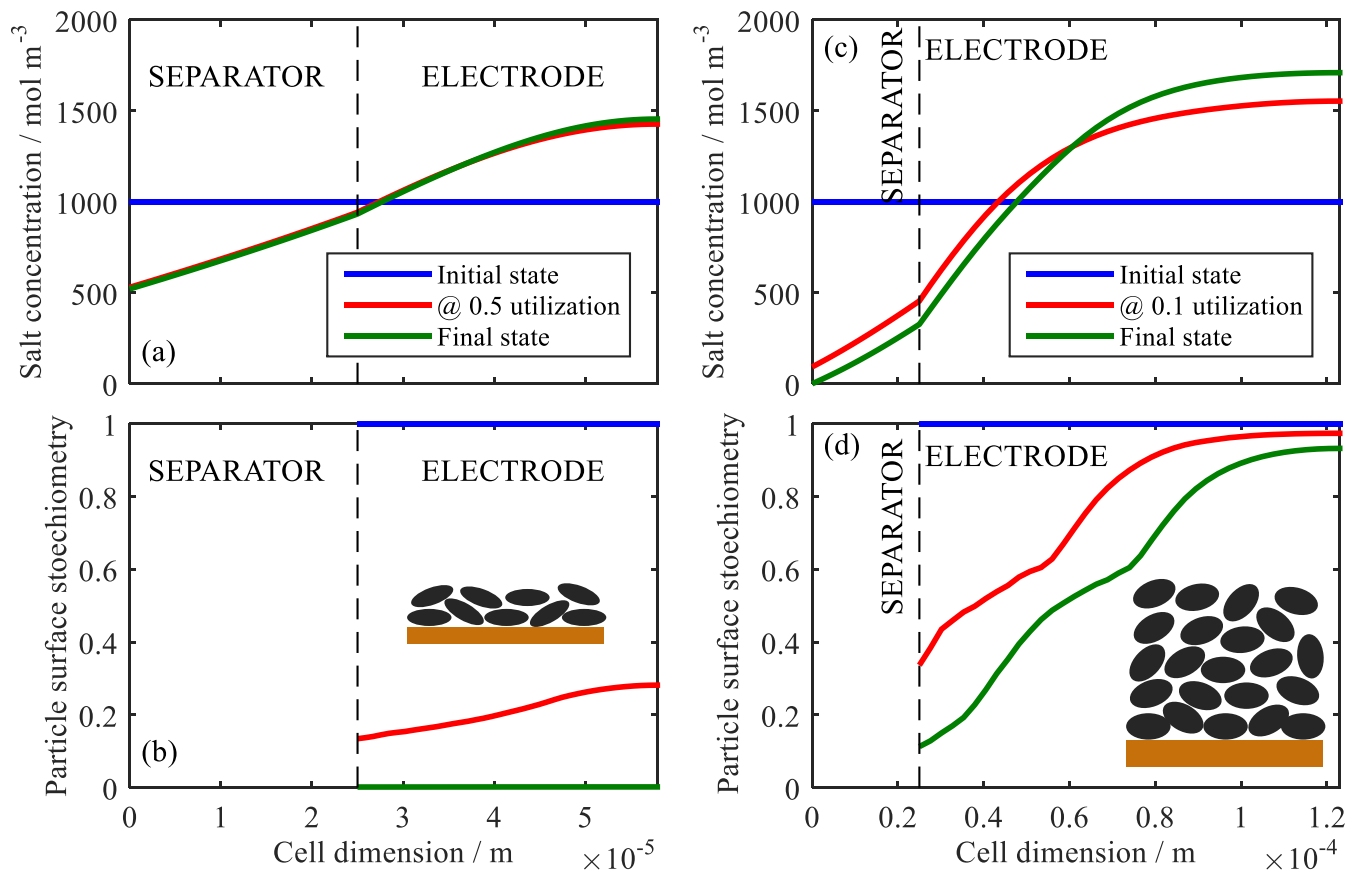

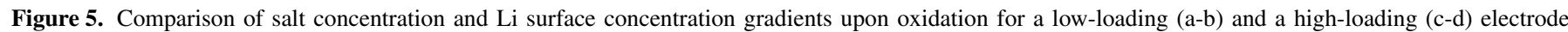

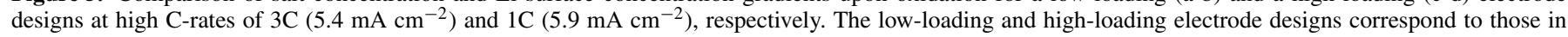
Figures 2d (L1D2) and 4f (L4D3), respectively. 

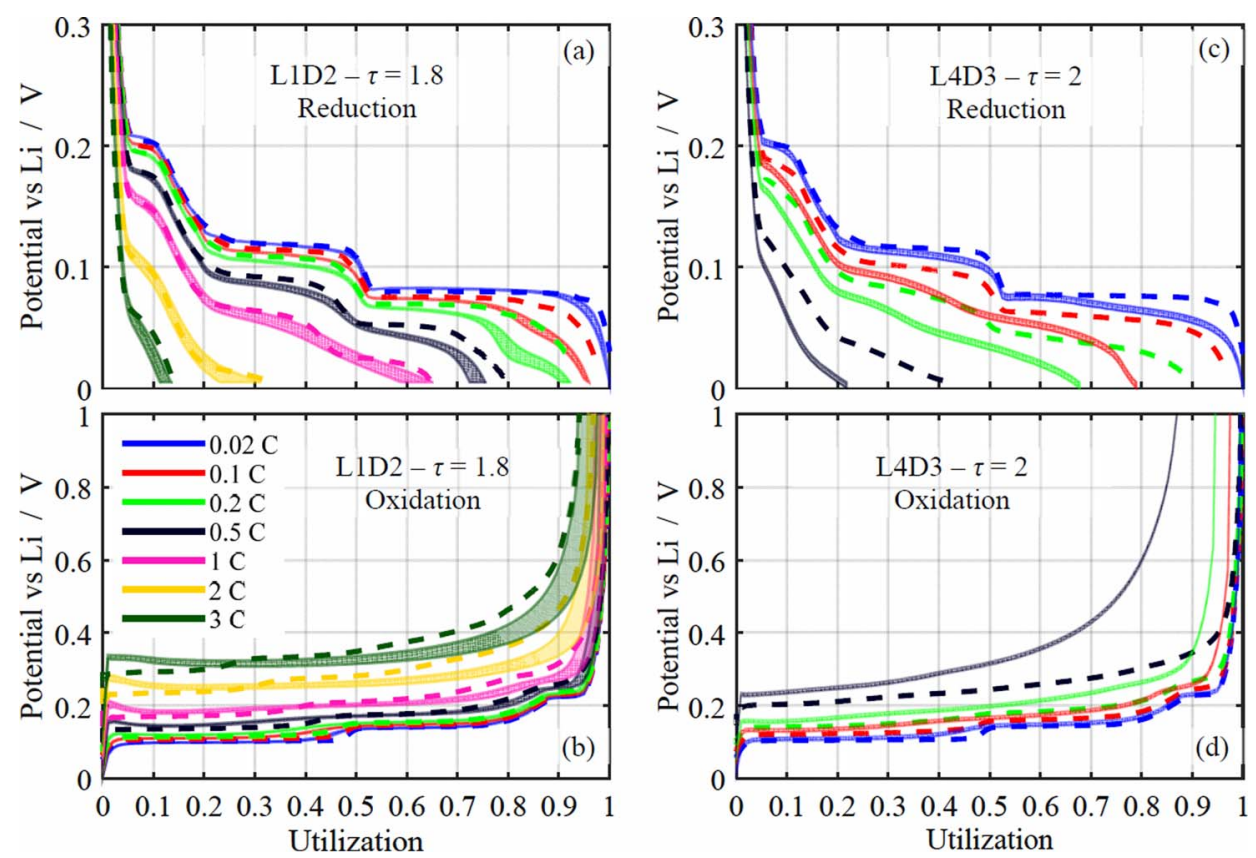

Figure 6. Comparison of graphite galvanostatic curves between experimental measurements (envelope curve) and P2D model simulations (dashed lines) for which tortuosity is calculated from the Bruggeman relation $(\tau$ $\left.=\varepsilon^{-0.5}\right)$, for a low-loading electrode design (L1D2) and a high-loading electrode design (L4D3). (a)-(b) Low-loading electrode, reduction and oxidation respectively; (c)-(d) Highloading electrode, reduction and oxidation respectively. The C-rate color code is the same for all subplots. electrodes displayed in Figures 2c-2d and 3f, 4f. When assuming Bruggeman relation, the tortuosity value drops from ca 6 to 2 for both electrodes. For the low-loading electrode in Figures $6 a-6 b$, the change in pore tortuosity value has only a minor effect on simulated potential, even at high C-rates; this is because liquid-phase limitations are not dominant for this electrode. However, for the high-loading electrode in Figures $6 c-6 d$, the model underpredicts simulated overpotential, thereby overpredicting areal capacities at all C-rates. The same observation is made for other high-loading electrode designs where liquid-phase polarization induced by the porous electrode is dominant (not shown here). Hence, the good match between galvanostatic simulations and experiments in the previous section validates the range of tortuosities determined from the impedance analysis of symmetric cells but also suggests that lowering electrode pore tortuosity is a good way toward improving power capabilities of high-energy-density electrodes.

Model analysis.-In a first part, the influence of electrodethickness increase at constant porosity of $\sim 40 \%$ is analyzed with regard to cell performance. An in-depth analysis of the rate-capability tests is then undertaken with the help of the P2D model. The model is used to breakdown the electrode overpotential into each polarization source for two electrode designs selected in this section, i.e. a low loading one and a high loading one.

The areal capacity of electrodes as a function of C-rate and electrode thickness is presented for graphite reduction in Figure 7a and oxidation in Figure $7 \mathrm{~b}$. The selected electrodes correspond to designs highlighted in colors in Figure 1. The electrodes are supposed uniform in composition and porosity, hence we assume the effect of electrode loading is only reflected in a change of thickness. In Figure 7, the capacity fade with increasing C-rate is more pronounced for high-loading electrodes. Additionally to larger expected liquidphase limitations, these electrodes undergo a higher current density than low-loading electrodes at a same C-rate. Nevertheless, highloading electrodes have higher areal capacities than low-loading electrodes at low C-rate $(<0.2 \mathrm{C})$, while having about the same overpotential (not shown here). At medium to high $\mathrm{C}$-rate, the situation is reversed, the areal capacity of high-loading electrodes declines while their overpotential increases further than that of low-loading electrodes. The decrease of areal capacity with C-rate is more pronounced during graphite reduction (Figure 7a) when compared with graphite oxidation (Figure 7b), as expected from the larger sensitivity of deliv- ered areal capacity to overpotential in reduction. The fast decrease of areal capacity upon reduction for high-loading graphite electrodes is an issue when considering fast charging of a $\mathrm{Li}$-ion cell.

The same electrodes as in Figure 7 are now represented in Figure 8 as normalized capacity against current density in order to have a fair comparison between the different electrode designs. Three distinct areas may be marked out in Figure 8 corresponding to three
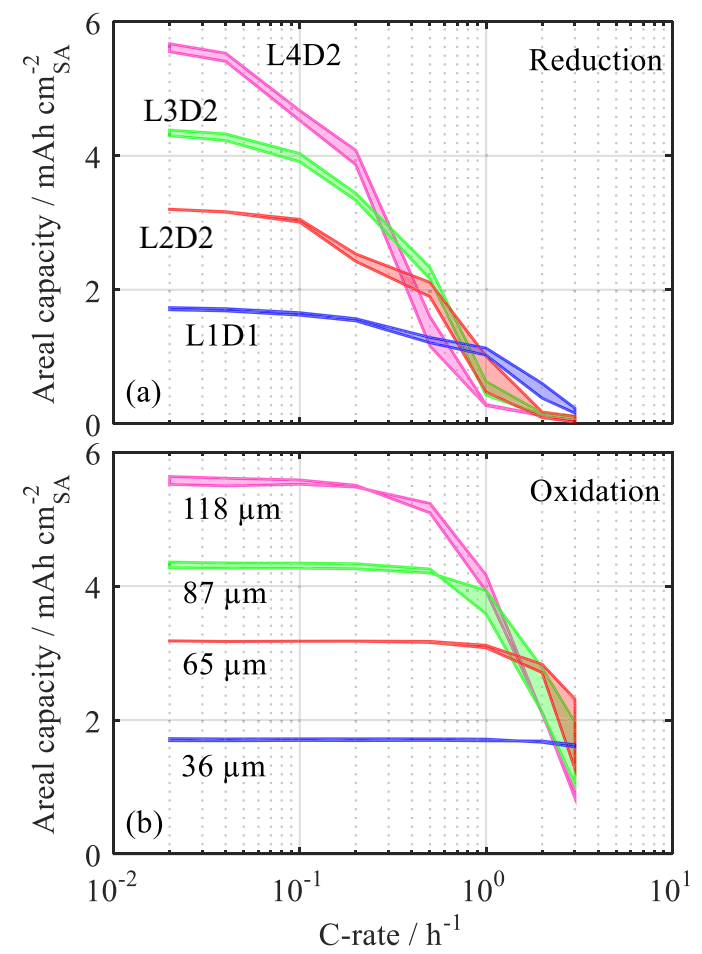

Figure 7. Areal capacities measured at different C-rates for galvanostatic reduction (a) and oxidation (b) of different graphite electrode designs with a nearly constant porosity of $40 \%$. These designs are represented with the corresponding colored circles in Fig. 1. (L1D1: $1.8 \mathrm{mAh} / \mathrm{cm}^{2}, \mathrm{~L} 2 \mathrm{D} 2: 3.3 \mathrm{mAh} / \mathrm{cm}^{2}$, L3D2: $4.4 \mathrm{mAh} / \mathrm{cm}^{2}$, L4D2: $5.9 \mathrm{mAh} / \mathrm{cm}^{2}$ ). 

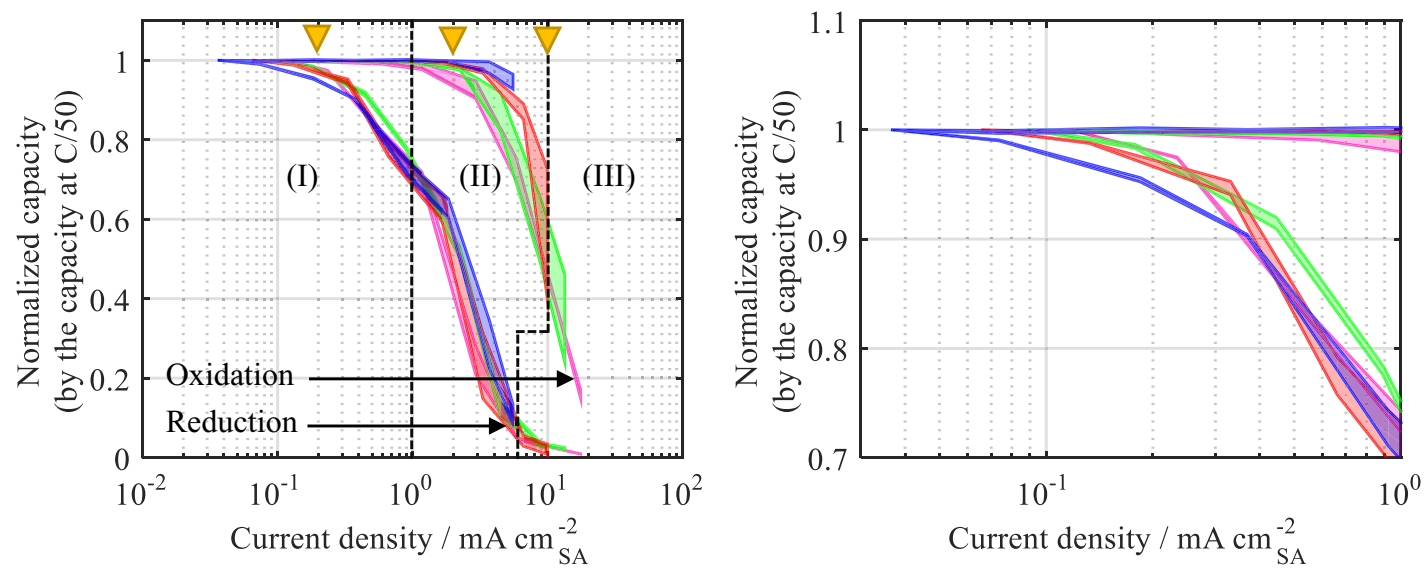

Figure 8. Reduction and oxidation normalized capacities as a function of current density for the four graphite electrode designs represented with the corresponding colored circles in Fig. 1 (L1D1: $1.8 \mathrm{mAh} / \mathrm{cm}^{2}$, L2D2: $3.3 \mathrm{mAh} / \mathrm{cm}^{2}$, L3D2: $4.4 \mathrm{mAh} / \mathrm{cm}^{2}$, L4D2: $5.9 \mathrm{mAh} / \mathrm{cm}^{2}$ ). Figures 9-10-11 refer to the three current densities marked by the yellow triangles.

ranges of current densities. The first area (I) approximately demarcates low current densities (under $1 \mathrm{~mA} \mathrm{~cm}^{-2}$ ) where limitations at the particle scale, i.e., surface reaction and solid diffusion, are supposedly dominant. If not for the inflexion observed on the reduction curves because of the additional overpotential mentioned in a previous section, it is observed that final utilizations are lower for low-loading electrodes than for high-loading electrodes (Figure 8b). Meanwhile, areal capacities upon graphite oxidation remain at theoretical value for all four electrode designs. A decomposition of the graphite potential curves and comparison with interpolated experimental data for L1D1 (blue curve) and L4D2 (pink curve) at $I=0.2 \mathrm{~mA} \mathrm{~cm}^{-2}$ is displayed in Figure 9. Starting from the basecase simulation, liquid-phase polarization is first shutdown (light blue area), then surface-reaction polarization (light red area) and finally solid-phase diffusion (green area). The remaining potential difference to the equilibrium curve (black solid line) corresponds to the Li CE overpotential (light purple area). By shutdown, it is meant that parameter values are set to extreme values so that limitations of corresponding physical phenonema are suppressed in the simulations. To this end, electrolyte conductivity, kinetic rate constant, and electrolyte/solid diffusion coefficient are set to high values. In addition, for electrolyte limitation shutdown, the lithium transference number and thermodynamic factor are set to one. Upon graphite reduction in Figures 9a and 9c, the final utilization of the low-loading electrode is less than that of the highloading electrode due to solid-diffusion limitation (see the green area). This is expected because a high-loading electrode has a larger interfacial area per geometric area $\left(a \times L_{\mathrm{el}}\right)$ than a low-loading electrode. Hence, at a same (low) current density, the pore-wall flux at each particle surface is lower for high-loading electrodes, which allows more time for lithium to diffuse from the surface to the center of the
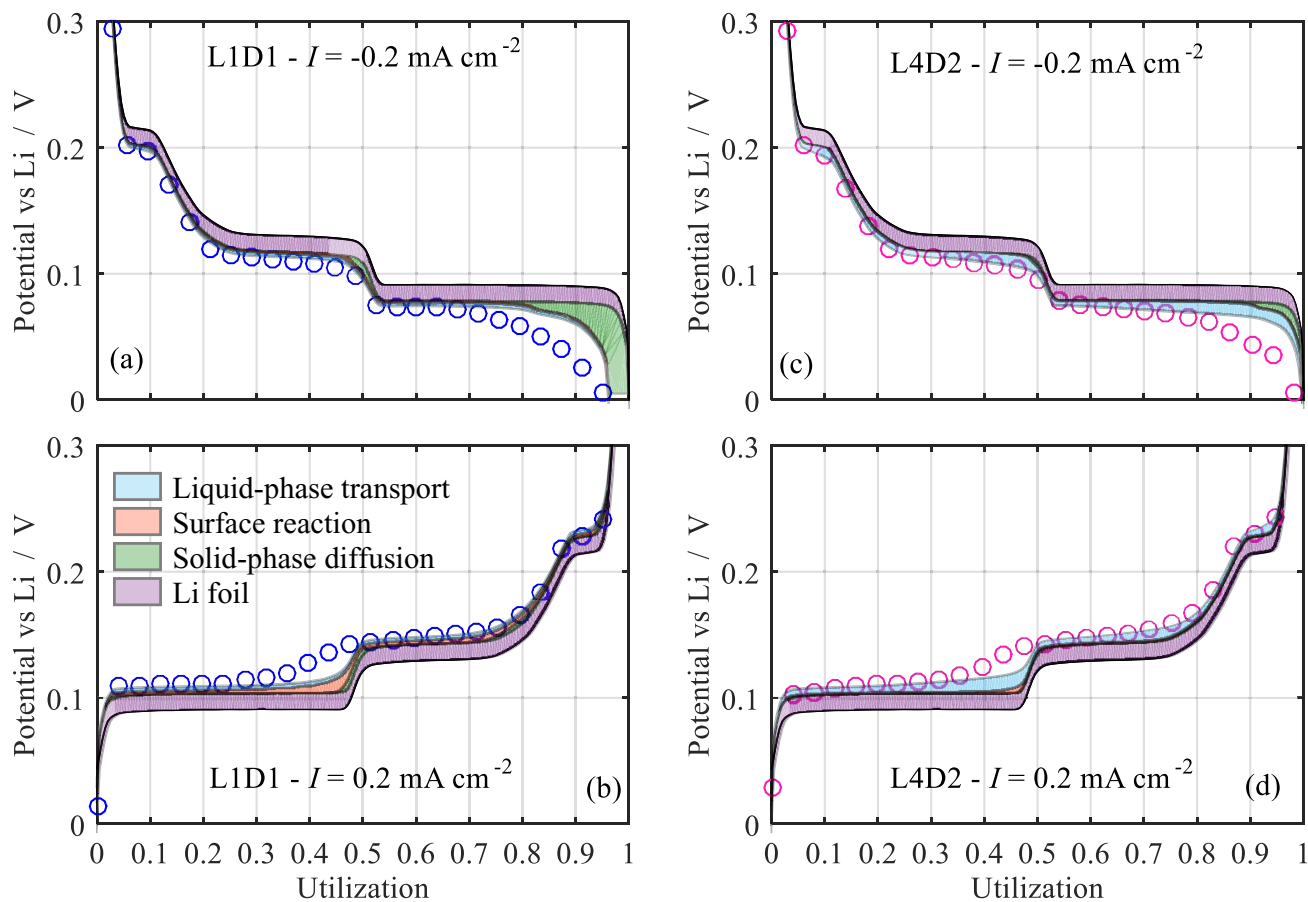

Figure 9. Decomposition of the graphite potential curve and comparison with interpolated experimental data (circles) at $I= \pm 0.2 \mathrm{~mA} \mathrm{~cm}^{-2}$ for a lowloading electrode L1D1 (a)-(b) and a high-loading electrode L4D2 (c)-(d). Starting from basecase simulation, liquid-phase polarization is first shutdown (light blue), followed by surface-reaction polarization (light red), and eventually solid-phase diffusion (green). Lithium foil polarization (light purple) forms the last overpotential source up to the equilibrium potential which is represented as a black solid line. 

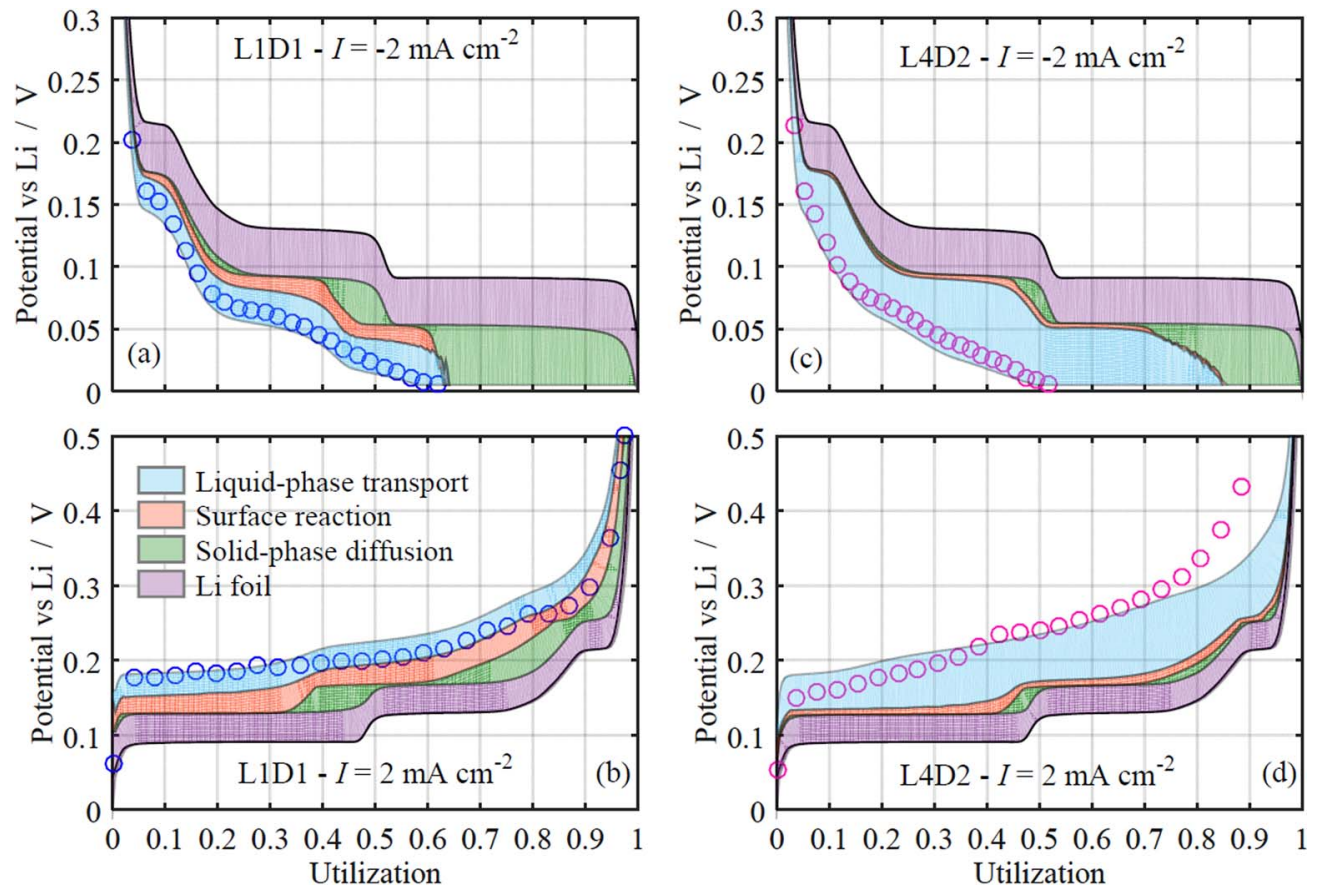

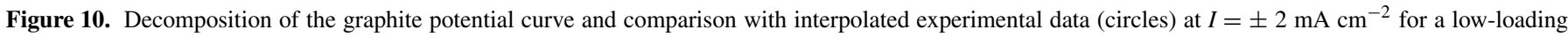

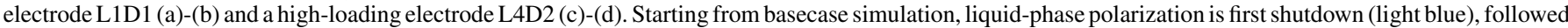

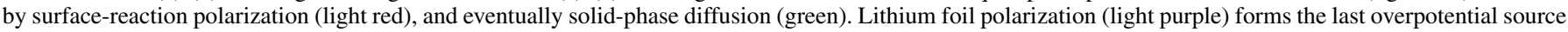
up to the equilibrium potential which is represented as a black solid line.

particles. Yet, it is noteworthy that liquid-phase polarization is more intense for the high-loading electrode even at this low current density (see the light blue area). Concerning graphite oxidation, no major difference is spotted between the overpotential decomposition of the two designs in Figures $9 \mathrm{~b}$ and 9d. Contrary to reduction, solid-diffusion limitations do not appear during oxidation. The reason is because the solid-diffusion coefficient is in average higher for fraction of inserted lithium $x$ between $0<x<0.5$ than $0.5<x<1$. Hence, these observed differences between reduction and oxidation may only be described by a variable solid-diffusion coefficient, as the one determined by PITT analysis in Ref. 39.

For the second area (II) represented in Figure 8, liquid-phase limitation starts to become dominant above a certain current density threshold that depends on the porous electrode design. The experimental final utilization of high-loading electrodes is now lower than that of low-loading electrodes for both graphite reduction and oxidation. A decomposition of the graphite potential curves and comparison with interpolated experimental data for L1D1 and L4D2 at $I=2 \mathrm{~mA} \mathrm{~cm}{ }^{-2}$ is displayed in Figure 10. It is observed that soliddiffusion limitation shifts the transition between the two plateaus compared to the equilibrium curve (see the green area), while surfacereaction and liquid-phase limitations contribute to a substantial overpotential at all utilizations. At $I= \pm 2 \mathrm{~mA} \mathrm{~cm}^{-2}$ in Figure 10, soliddiffusion and surface-reaction polarizations of the low-loading electrode remain larger than that of the high-loading electrode. However, at this current density, liquid-phase limitation takes over and the final utilization of the high-loading electrode decreases consequently upon reduction. In Figure 10b, the difference between experimental and simulated potential curves that was pointed out during oxidation of the low-loading electrode in Figure 2d is again observed at mediumto-large extent of oxidation. Interestingly, this difference tends to disappear for higher-loading electrode designs before any potential shoot up to $1.5 \mathrm{~V}$ vs Li (Figures 4d-4f) and the basecase simulation in Figure $10 \mathrm{~d}$ has an even lower potential than the interpolated experimental data at large extent of oxidation. Considering that high-loading electrodes are less sensitive to surface-reaction and solid-diffusion limitations than low-loading electrodes, and that it appears for the low-loading electrode (Figure 10b) after the phase transition from stage I to stage II, we suggest that this difference observed for low-loading electrodes may be related to solid-diffusion limitation. The solid-diffusion coefficient seems underestimated for graphite oxidation. As for the discrepancy observed for L2, L3 and L4 electrodes between model simulation and experimental data for large extent of graphite oxidation at current densities of $2 \mathrm{~mA} \mathrm{~cm}^{-2}$ or more (Figures $4 \mathrm{~d}-4 \mathrm{f}$ ), an explanation is attempted by analyzing Figure 10d. The interpolated final utilization value is less than unity whereas the simulation predicts a full oxidation of the electrode. Conversely, for the low-loading electrode in Figure 10b, both interpolated and simulated data show a full oxidation of the electrode. This confirms that the decrease in final utilization observed for the experimental curve of Figure 10d relates to liquid-phase limitation. The experimentally lower end-of-oxidation utilization may result from non-uniformities of electrode geometry. The salt concentration gradient remains between [0.5-1.5] $\mathrm{mol} \mathrm{L}^{-1}$ for the basecase simulation in Figure 10d, hence it should not be related to local salt precipitation or depletion. However, the model does not account for pore bottlenecks or contacting particles that may affect locally the pore-wall flux and lithium ion mobility in the electrolyte, hence resulting in a nonuniform emptying of the particles. In the model, salt concentration within the pores is assumed uniform at a specified position across the electrode. However, at high current density, it is known that radial diffusion within pores should be accounted for. ${ }^{44}$ The effect of pore geometry is expected to be magnified in high-loading electrodes, especially during deep charge/discharge at high current densities. To conclude, the simulation/experiment discrepancies observed at high current densities for large extent of graphite oxidation (Figure 4) may be due to electrode local non-uniformities that affect potentials and concentration gradients across the cell.

Now moving on to the third area (III) represented in Figure 8, both low and high loading electrodes yield about the same final utilization values for graphite reduction and oxidation. The final utilization value is not influenced by differences of liquid-phase polarization induced by the porous electrode design. A decomposition of the graphite 

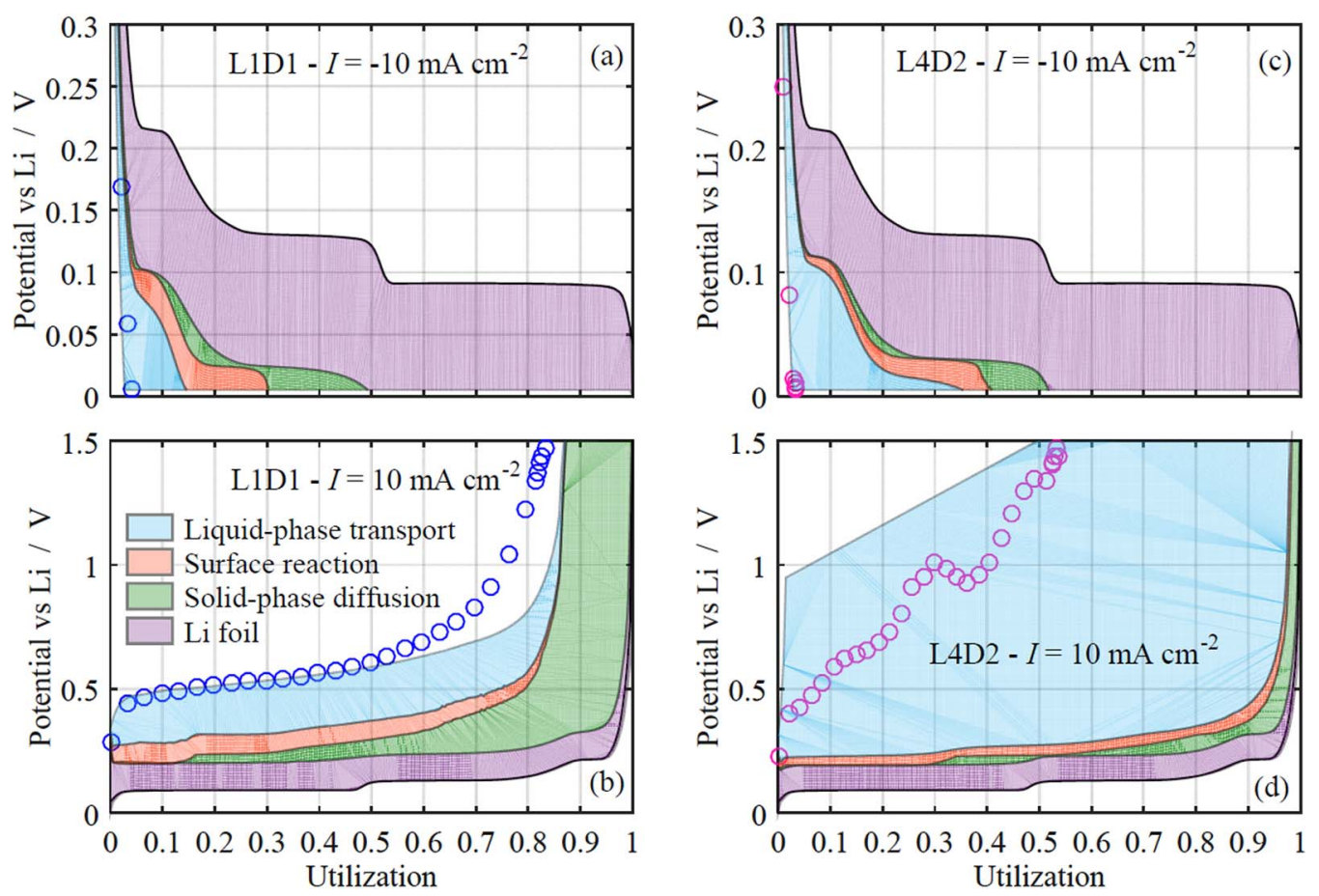

Figure 11. Decomposition of the graphite potential curve and comparison with interpolated experimental data (circles) at $I= \pm 10 \mathrm{~mA} \mathrm{~cm}^{-2}$ for a lowloading electrode L1D1 (a)-(b) and a high-loading electrode L4D2 (c)-(d). Starting from basecase simulation, liquid-phase polarization is first shutdown (light blue), followed by surface-reaction polarization (light red), and eventually solid-phase diffusion (green). Lithium foil polarization (light purple) forms the last overpotential source up to the equilibrium potential which is represented as a black solid line.

potential curves and comparison with interpolated experimental data for L1D1 and L4D2 at $I=10 \mathrm{~mA} \mathrm{~cm}^{-2}$ is displayed in Figure 11. For L1D1, a coin cell is cycled up to $10 \mathrm{C}$ hence allowing to interpolate data at $I=10 \mathrm{~mA} \mathrm{~cm}^{-2}$. Consistent with previous observations, soliddiffusion and surface-reaction limitations of the low-loading electrode design are still larger than that of the high-loading one. Upon graphite reduction in Figures 11a and 11c, the sum of all polarization sources is strong enough ( $>0.3 \mathrm{~V}$ vs $\mathrm{Li}$ ) to make the cell potential hit instantly the cutoff voltage value for both electrode designs. The Li CE overpotential is especially large (light purple area) compared with the porous electrode surface-reaction and solid-diffusion overpotentials. Upon graphite oxidation in Figures $11 \mathrm{~b}$ and $11 \mathrm{~d}$, the shoot up in potential is triggered by a solid-phase Li concentration drop to zero at the graphite particle surface and a salt concentration drop to zero at the Li CE for the low- and high-loading electrode designs, respectively. The lowloading electrode undergoes large liquid-phase polarization; however final utilization is driven by solid-diffusion limitation. The pore-wall flux at the particle surface is large enough so that solid Li concentration drops to zero at the particle surface while some lithium is still trapped in the particle core. It is noted that small particles are emptying at a faster rate than big particles because of larger surface-to-volume ratio and shorter diffusion length. Besides, the basecase simulated potential curve of the high-loading electrode shoots to the cutoff voltage value almost instantly (Figure 11d). The local salt concentration drops to zero at the Li CE surface in this case. The polarization breakdown shows that almost all capacity of the L4D2 electrode could be retrieved if liquid-phase overpotential could be alleviated. However, the experimental curve lies in between the basecase simulation and that without electrolyte limitation (i.e., $\sim$ middle of the light blue area), thereby attesting once again that the experimental utilization decrease of high-loading electrodes is ascribed to liquid-phase limitation in agreement with earlier literature reports. ${ }^{12}$ At current densities above ca $5 \mathrm{~mA} \mathrm{~cm}^{-2}$, experimental potential curves of all designs are jagged in the same way as in Figure 11d, resulting in experiment repeats that produced large ranges of final utilization (See error bars in Figs. 4a-4c). Together with local non-uniformities present in high- loading electrodes that are not accounted for in the model, a possible explanation for what is observed in experiments at these high current densities is that the Li CE does not behave as simply as it is described in the model. Its surface is not smooth and may change with repeated cycling at high current densities (formation of dendrites).

A breakdown of the electrolyte properties for the basecase simulation presented in Figure $10 \mathrm{c}$ is illustrated in Figure 12. The L4D2 electrode shows large liquid-phase polarization at $2 \mathrm{~mA} \mathrm{~cm}^{-2}$ $(\sim 0.35 \mathrm{C})$, hence further investigation is undertaken to assess the contributions of all four electrolyte parameters. In Figure 12a, electrolyte properties are turned off one after the other, beginning with the electrolyte conductivity (light blue), then the thermodynamic factor (light red) and finally the transference number or the diffusion coefficient (green). Shutting down the transference number or the diffusion coefficient results in the exact same effect as it zeroes the salt concentration gradient in the electrolyte. The salt concentration gradient obtained from the basecase simulation is represented in Figure $12 \mathrm{~b}$ at a mean utilization of 0.4 in the graphite electrode. This salt concentration gradient quickly forms in the first minutes of reduction and remains almost constant over time. From Figure 12a, it is observed that the ionic conductivity induces a small and nearly constant overpotential for the liquid phase polarization $(\sim 10-15 \mathrm{mV})$ (see the light blue area). The local ionic conductivity value is relatively high and lies between $0.6-0.8 \mathrm{~S} \mathrm{~m}^{-1}$ over the whole graphite reduction across the cell. The thermodynamic factor has a slightly larger influence on the cell overpotential $(\sim 20 \mathrm{mV})$ than ionic conductivity (see the light red area). This property appears in the second term of the extended Ohm's law equation that describes liquid-phase transport and that accounts for concentration overpotential. Hence, the large overpotential value due to the thermodynamic factor relates to the large salt concentration gradient observed in Figure 12b (See the red curve). Finally, shutting down the transference number or diffusion coefficient zeroes the salt concentration gradient across the cell (see the green area). The liquid-phase potential $\Phi_{2}$ is then equal to zero throughout the cell, which cancels variations of the particle surface utilization across the graphite electrode as seen from the 

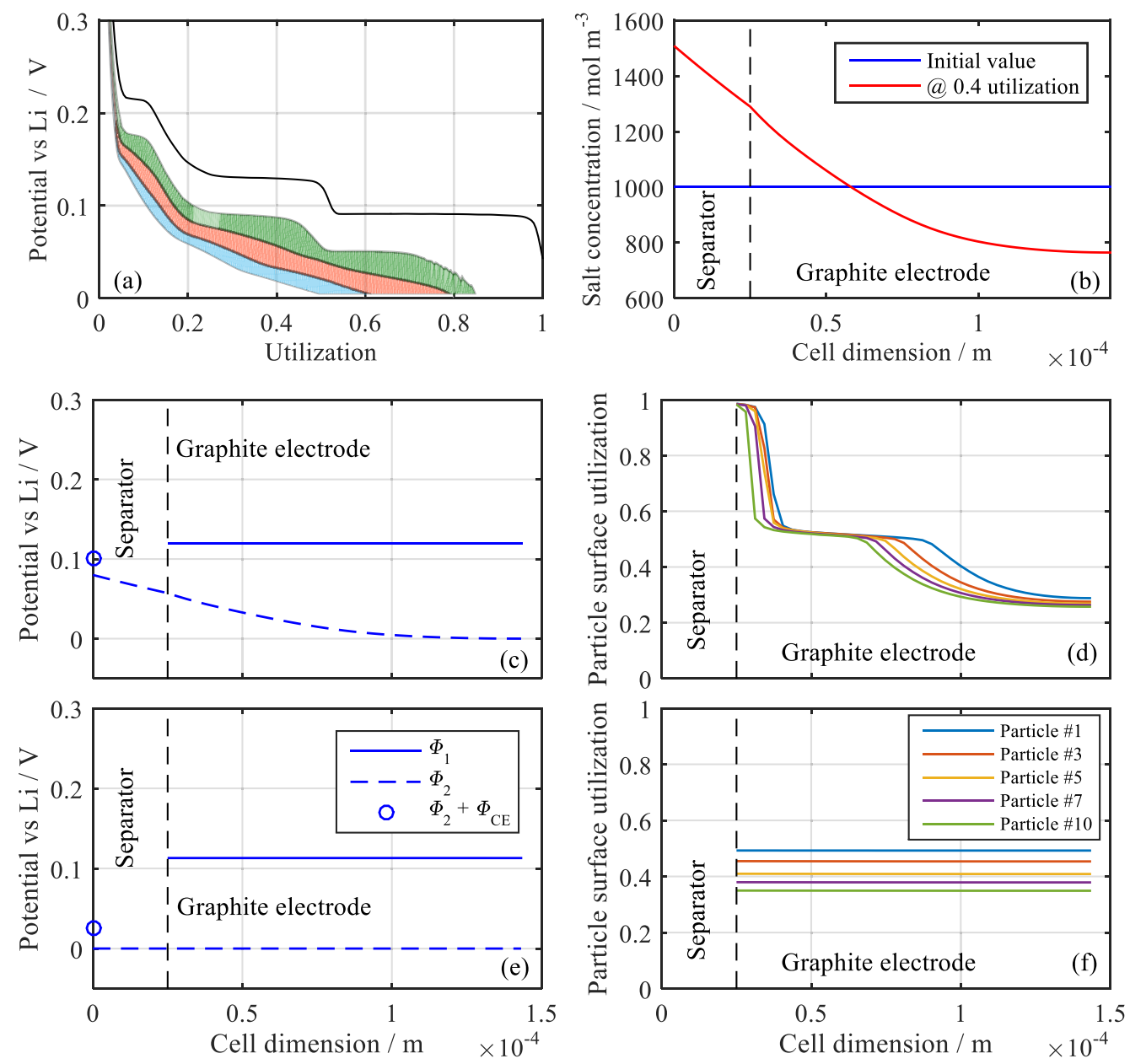

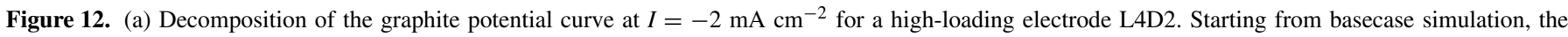

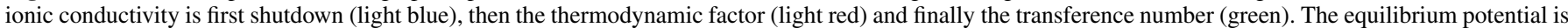

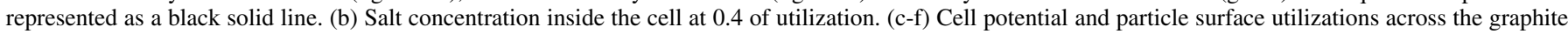

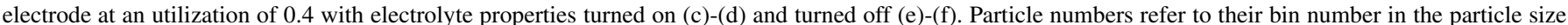
distribution, ranging from the smallest (\#1) to the largest (\#10) (See Fig. S2).

difference between Figures 12c-12d (electrolyte turned on) and Figures $12 \mathrm{e}-12 \mathrm{f}$ (electrolyte turned off) for a mean utilization of 0.4 . The solid-phase potential $\Phi_{1}$ is nearly constant across the electrode (see Figures $12 \mathrm{c}$ and 12e) since the effective solid-phase conductivity is high. Through the solid-phase potential, the influence of the PaSD is observed on the upper contour of the green area in Figure 12a, with all electrolyte properties shutdown. The shape of this contour curve differs from the shape of the equilibrium curve (solid black line) around utilization of 0.5 and $0.7-0.8$. The slope is smoother because, as shown in Figure 12f, small particles fill faster than big particles, hence lowering gradually the equilibrium potential and thereby, the solid-phase and cell potential. When a salt concentration gradient kicks in (see the curve between the light red and green areas in Figure 12a), the potential curve is further smeared out because of variations of the liquid-phase potential with time. To summarize this paragraph, the formation of a large salt concentration gradient is the main factor responsible for the large overpotential due to liquid-phase limitations.

Finally, the graphite-electrode model is used in a full-cell model vs a positive NMC (111) electrode to predict the occurrence of Li plating on the graphite electrode for various cell designs. The negative-topositive loading balancing is kept constant at 1.1 while electrode loadings (thickness) and densities (porosity) of the negative and positive electrodes are varied accordingly. Li plating is prone to occur if the difference between the solid and liquid phase potentials becomes negative in the graphite electrode (at the interface with the separator). Hereafter, cell designs are compared at identical current densities of 1 and $2 \mathrm{~mA} \mathrm{~cm}^{-2}$ (see Figure 13). However, it is noteworthy that two different cell designs would not operate at the same current density in two battery packs having the same power output performance. In this situation, the battery pack made out of cells with the lowest electrode loadings would have a larger cell geometric area; hence, the cells would operate at a lower current density than those with a larger electrode loading. It is however beyond the scope of this study to provide a detailed review of cell design optimization for a specific application (e.g., for EVs). Yet, the information given by Figure 13 remains relevant to enlighten once again the conclusions of the analysis of the graphite-electrode model. In Figure 13a, Li plating is predicted to occur for two extreme graphite electrode designs: either for small loadings of ca $1.5-2 \mathrm{mAh} \mathrm{cm}^{-2}$, regardless of the electrode porosity or for very high-loading and non porous electrodes. For low-loading designs, the simulation ends because of a sudden cell potential shoot up to the cutoff voltage limit at $4.3 \mathrm{~V}$ (vs $\mathrm{Li}$ ) that is caused by the complete filling of the smaller graphite particles. This corresponds to solid-diffusion limitations upon graphite reduction in low-loading electrodes, which is detailed in the Model analysis section. On the other hand, the Li plating observed for high-loading and dense electrode designs is caused by a large gradient of the liquid-phase potential across the cell, which is again, partly due to a large salt concentration gradient across the cell. When doubling the current density in 

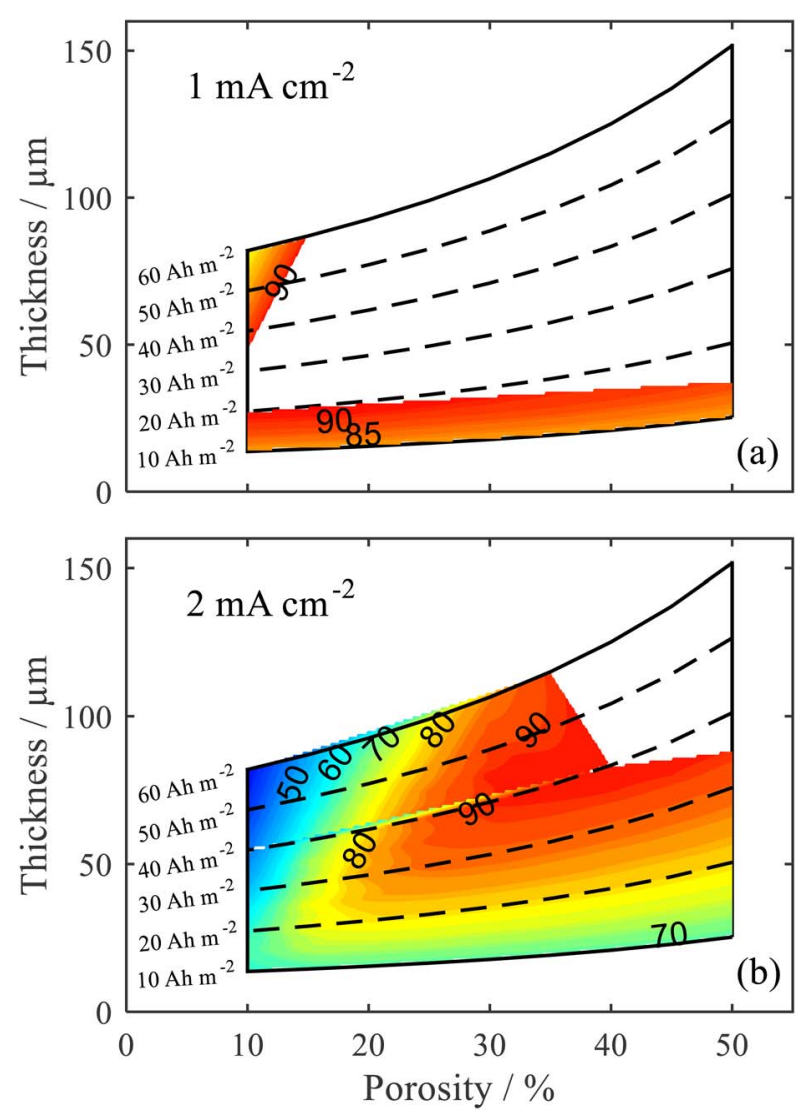

Figure 13. Prediction of the occurrence of Li plating for various designs of negative graphite electrodes at $1 \mathrm{~mA} \mathrm{~cm}^{-2}$ (a) and $2 \mathrm{~mA} \mathrm{~cm}^{-2}$ (b). Cell balancing (negative to positive loading ratio) is set to 1.1. Cell state-of-charge at which the possible occurrence of Li plating are indicated with a colored contour map and numbers (in \%). Iso-loading lines are plotted in black with either solid or dashed lines.

Figure $13 \mathrm{~b}\left(2 \mathrm{~mA} / \mathrm{cm}^{2}\right.$ instead of $\left.1 \mathrm{~mA} / \mathrm{cm}^{2}\right)$, these two possible electrode limitations that lead to Li plating extend to other intermediate designs that did not initially show any Li plating at $1 \mathrm{~mA} / \mathrm{cm}^{2}$. The onset SOC at which the Li plating occurs is shown to decrease with the increase in current density.

\section{Conclusions}

High-loading electrodes are capable of storing large amounts of $\mathrm{Li}$ /energy, which is a requirement for battery packs in order to meet customer's expectation in terms of battery autonomy. However, the downside is that the power capability of such electrodes is limited. In this work, a combined experimental/modeling approach is carried out in order to shed light on the performance limitations of high-loading electrodes. At any set current density, high-loading electrodes suffer less particle-scale limitation than low-loading electrodes do. This is because they have a larger active surface area per geometric surface area $\left(a \times L_{\mathrm{el}}\right)$, hence the pore-wall flux at the particle surface is smaller. It is observed through full-cell simulations that acute particle-scale limitations in low-loading graphite electrode may also lead to the occurrence of Li plating at current densities above $1 \mathrm{~mA} \mathrm{~cm}{ }^{-2}$. The decrease of the solid-diffusion coefficient for composition between $x=0.5-1$, with regard to $x=0-0.5$ is responsible for solid-diffusion limitation observed on low-loading electrodes upon graphite reduction at low current densities. However, at medium to high current densities $\left(>1 \mathrm{~mA} \mathrm{~cm}^{-2}\right.$ for graphite electrodes studied here), high-loading electrodes undergo large liquid-phase limitation because of longer diffusion paths compared to low-loading electrodes. A large salt concentration gradient forms across the cell, which results in effects within both liquid and solid phases. The liquid-phase potential gradient mirrors the salt concentration gradient, hence a large liquid-phase overpotential develops across the cell. Then this liquidphase potential gradient entails nonuniformities in terms of local state-of-charge along the depth of the electrodes. Both this potential gradient and SoC nonuniformity may yield Li plating, depending on electrodes design, at the boundary between the graphite electrode and the separator in a full cell as observed in performed simulations. Along with this drawback, large liquid-phase overpotential lowers the cell potential hence decreasing cell power output. Cutoff potentials may even be reached before all cell capacity is delivered. Solutions to prevent large liquid-phase limitations are of two kinds, i.e., either work on the porous electrode microstructure or improve the electrolyte properties. A decrease of electrode pore tortuosity is especially sought as it multiplies by a factor of 2 to 3 , for electrodes studied here, the effective diffusion path lengths in the graphite electrode pores.

\section{Acknowledgment}

S. Malifarge is grateful to ANRT for partially supporting the funding of this research work. ZEON Corporation is acknowledged for support in this work. B. Fleutot is gladly thanked for discussions and all conductivity measurements performed on the graphite electrodes. D. Gruet is acknowledged for the electrode thickness measurements.

\section{ORCID}

\section{Charles Delacourt (10 https://orcid.org/0000-0001-5241-5441}

\section{References}

1. WHO Regional Office for Europe OECD, Economic cost of the health impact of air pollution in Europe: Clean air, health and wealth., p. 1, (2015) http:// www.euro.who.int/en/media-centre/events/events/2015/04/ehp-mid-term-review/ publications/economic-cost-of-the-health-impact-of-air-pollution-in-europe

2. Z. Du, D. L. Wood, C. Daniel, S. Kalnaus, and J. Li, J. Appl. Electrochem., 47(3), 405 (2017).

3. T. Danner et al., J. Power Sources, 334, (2016).

4. S. B. D. Stewart et al., J. Electrochem. Soc., 155, A253 (2008).

5. C. Fongy, A.-C. Gaillot, S. Jouanneau, D. Guyomard, and B. Lestriez, J. Electrochem. Soc., 157, A885 (2010)

6. C. Fongy, S. Jouanneau, D. Guyomard, J. C. Badot, and B. Lestriez, J. Electrochem. Soc., 157, A1347 (2010).

7. H. Zheng et al., J. Electrochem. Soc., 157, A1060 (2010).

8. H. Zheng, J. Li, X. Song, G. Liu, and V. S. Battaglia, Electrochim. Acta, 71, 258 (2012).

9. H. Zheng, L. Tan, G. Liu, X. Song, and V. S. Battaglia, J. Power Sources, 208, 52 (2012).

10. N. Ogihara, Y. Itou, T. Sasaki, and Y. Takeuchi, J. Phys. Chem. C, 119, 4612 (2015).

11. J. Shim and K. A. Striebel, J. Power Sources, 130, 247 (2004).

12. H. Buqa, D. Goers, M. Holzapfel, M. E. Spahr, and P. Novák, J. Electrochem. Soc., 152, A474 (2005).

13. M. Singh, J. Kaiser, and H. Hahn, J. Electrochem. Soc., 162, A1196 (2015)

14. M. Singh, J. Kaiser, and H. Hahn, J. Electroanal. Chem., 782, 245 (2016).

15. K. G. Gallagher et al., J. Electrochem. Soc., 163, A138 (2016).

16. N. A. Cañas et al., Carbon N. Y., 116, 255 (2017).

17. P. P. R. M. L. Harks, F. M. Mulder, and P. H. L. Notten, J. Power Sources, 288, 92 (2015).

18. S. J. Harris, E. K. Rahani, and V. B. Shenoy, J. Electrochem. Soc., 159, A1501 (2012).

19. K. Kitada et al., J. Power Sources, 301, 11 (2016).

20. P. Pietsch, M. Hess, W. Ludwig, J. Eller, and V. Wood, Sci. Rep., 6, 27994 (2016).

21. S. Taminato et al., Sci. Rep., 6, 28843 (2016).

22. D. S. Eastwood et al., Adv. Energy Mater., 4, 1 (2014).

23. S. J. Harris, A. Timmons, D. R. Baker, and C. Monroe, Chem. Phys. Lett., 485, 265 (2010).

24. J. Newman and W. Tiedemann, AIChE J., 21, 25 (1975),

25. T. F. Fuller, M. Doyle, and J. Newman, J. Electrochem. Soc., 141(4), 982 (1994).

26. V. Srinivasan and J. Newman, J. Electrochem. Soc., 151, A1530 (2004).

27. S. Yu, Y. Chung, M. S. Song, J. H. Nam, and W. Il Cho, J. Appl. Electrochem., 42, 443 (2012).

28. S. Yu, S. Kim, T. Y. Kim, J. H. Nam, and W. Il Cho, Bull. Korean Chem. Soc., 34, 79 (2013).

29. A. Maheshwari, M. A. Dumitrescu, M. Destro, and M. Santarelli, J. Power Sources, 307, 160 (2016).

30. R. Zhao, J. Liu, and J. Gu, Appl. Energy, 139, 220 (2015).

31. M. D. Levi and D. Aurbach, J. Phys. Chem. B, 101, 4641 (1997).

32. D. Aurbach et al., J. Electrochem. Soc., 145, 3024 (1998). 
33. E. Markevich, M. D. Levi, and D. Aurbach, J. Electroanal Chem , 580, 231 (2005).

34. L. O. Valøen and J. N. Reimers, J. Electrochem. Soc., 152, A882 (2005).

35. H. Lundgren, M. Behm, and G. Lindbergh, J. Electrochem. Soc., 162, A413 (2014).

36. S. G. Stewart and J. Newman, J. Electrochem. Soc., 155, F13 (2008).

37. M. Farkhondeh, M. Pritzker, M. Fowler, and C. Delacourt, Electrochem. commun., 67, 11 (2016)

38. M. Mastali, M. Farkhondeh, S. Farhad, R. A. Fraser, and M. Fowler, J. Electrochem Soc., 163, 2803 (2016).
39. S. Malifarge, B. Delobel, and C. Delacourt, J. Electrochem. Soc., 164, A3925 (2017).

40. S. Malifarge, B. Delobel, and C. Delacourt, J. Electrochem. Soc., 164, E3329 (2017).

41. S. Malifarge, B. Delobel, and C. Delacourt, J. Power Sources, 343, 338 (2017).

42. J. Landesfeind, J. Hattendorff, A. Ehrl, W. A. Wall, and H. A. Gasteiger, J. Elec trochem. Soc., 163, A1373 (2016).

43. S.-L. Wu et al., J. Electrochem. Soc., 159, A438 (2012).

44. J. Mao, W. Tiedemann, and J. Newman, J. Power Sources, 271, 444 (2014). 